\title{
Analysis of Transmission Cost Allocation Strategies with Reliability for Deregulated Systems
}

\author{
Shaik. Muqthiar Ali, Mareddy Padma Lalitha, N. Visali
}

\begin{abstract}
This paper presents a learning review of various strategies related to the improvement of the reliability for the deregulated system, for instance, Genetic Algorithms (GA), Tabu Search (TS), heuristic calculations and system based techniques. These methodologies were produced for advancing reliability as either software or hardware exclusively. Besides, the cost segments related with limit utilize and reliability advantage charges are resolved and various optimization techniques are acknowledged of action of the goal work.
\end{abstract}

Index Terms: Transmission cost allocation (TCA), Allocation Tier (AL) Transacted Power(TPO) deregulated electricity market, loss cost, Genetic algorithm, TS, SA.

\section{INTRODUCTION}

The TCA to system entities is an aim of deregulated power system. It is mostly approved that the concern for the use of transmission system should conceal each cost and supports a trivial tier of profit for the possessors of the services. The obstruction converts how to assign these costs between the clients. It is fair mode which delivers them with exact AL built on economic tiers. The TCA ideas are the most regular than the wheeling which was the transference of TPO amongst 2 or more utilities over a transmission network of the $3^{\text {rd }}$ one, cost for transmission procedure and the methodology to which it is processed and major focus issue in the power industry because of the progress in transmission abilities, the cost differentials concerning Generating companies and the melodramatic evolution in non-utility generation role. In some portions of the globally electricity supply industries endures transformation from regulated to deregulated structural. Several new concerns such as transmission embedded cost allocation, loss allocation, congestion management etc., occurs owing to this transformation

The chief purpose of some transmission pricing method is to familiarize an adequate rivalry in the electricity zone and afford proficient economic signals. Transmission pricing approaches are the general procedures of transmission costs into complete transmission charges. Generally, characteristics of transmission cost allocation systems are to offer location signals and motivations to reassure effective use of the transmission services. They also fulfill certain terms to evade cross-subsidies, to be clear and easier to execute, to confirm cost recovery, to deliver some suitable economic signals and to have continuousness with time.

\section{RECENT RESEARCH WORKS: A BRIEF REVIEW}

In literature, there has been a lot of research is proceeded for transmission allocation with consistency for the deregulated power system. A few of them are revised at this time,

Moradiet al. [1] has executed a consolidated GA/Particle Swarm Optimization (PSO) for the ideal area and estimating of Distributed age (DG) on conveyance frameworks. DG sources were getting more protuberant in conveyance frameworks inferable from the incremental nerves for electrical vitality. The expectation was to minimalize organize control misfortunes, better voltage direction and enhance the voltage dependability in the casing work of framework activity and security controls in outspread dispersion frameworks.

Amanullaet al. [2] have existed a power conveyance framework reconfiguration system as the unwavering quality and the power misfortune. Probabilistic dependability models were utilized to survey the unwavering quality of the heap focuses. A calculation for watching the negligible slice sets was utilized to see the insignificant arrangement of components performing among the feeder and some heap point. The ideal status of the changes to augment the unwavering quality and limit the genuine power misfortune was gotten by a double molecule swarm improvement based hunt calculation.

Borges et al. [3] have reconnoitered reliability models and approaches for valuing renewable energy resources impact on electrical generation convenience. Those models and procedures may be used to appraise the effects on the distribution systems reliability of distributed generation integration, while they were founded on renewable energy sources. The chief physiognomies of renewable resources models that have been established for wind, small hydro, solar and biomass, the leading techniques for reliability valuation of distribution systems with such resources cohesive. 
Analysis of Transmission Cost Allocation Strategies with Reliability for Deregulated Systems

Table. 1 Comparison analysis of different methods

\begin{tabular}{|c|c|c|c|c|}
\hline Year & Authors & Method & Objective function & Drawbacks \\
\hline 2012 & $\begin{array}{l}\text { Rahmat-AllahHooshmandet } \\
\text { al. }[32]\end{array}$ & PSO algorithm & $\begin{array}{l}\text { Transmission expansion } \\
\text { planning problems }\end{array}$ & $\begin{array}{l}\text { High complex reliability optimization } \\
\text { problem, considering optimal placement of } \\
\text { both RCSs and DG. }\end{array}$ \\
\hline 2013 & George A et al. [33] & $\begin{array}{l}\text { MW-Mile } \\
\text { approaches }\end{array}$ & $\begin{array}{c}\text { Transmission cost } \\
\text { allocation to network users }\end{array}$ & $\begin{array}{l}\text { Reliability quality edge, since the limit of } \\
\text { transmission offices is typically bigger in } \\
\text { the power framework }\end{array}$ \\
\hline 2012 & Cui et al. [34] & $\begin{array}{l}\text { MIMO-OFDM } \\
\text { systems }\end{array}$ & $\begin{array}{l}\text { Optimal power allocation } \\
\text { problems }\end{array}$ & $\begin{array}{l}\text { Transmitter enhancement for different } \\
\text { receiving wire cell frameworks and } \\
\text { explored incremental power portion } \\
\text { systems joined with BC-MAC duality }\end{array}$ \\
\hline 2011 & Wei-Chang Yehet al. [35] & $\mathrm{ABC}$ & $\begin{array}{l}\text { Reliability redundancy } \\
\text { allocation problem }\end{array}$ & $\begin{array}{l}\text { The classification of obliged nonlinear } \\
\text { blended whole number streamlining issues }\end{array}$ \\
\hline 2013 & Molina et al. [36] & $\begin{array}{l}\text { Aumann-Shapley } \\
\text { method }\end{array}$ & $\begin{array}{l}\text { Allocate the costs of the } \\
\text { transmission system }\end{array}$ & $\begin{array}{l}\text { Combinatorial nature, the issue measure } \\
\text { develops exponentially with the number of } \\
\text { operators and strategy turns out to be } \\
\text { computationally unfeasible }\end{array}$ \\
\hline $\begin{array}{c}2012 \\
\& 2013\end{array}$ & $\begin{array}{l}\text { Morales et al. [37], } \\
\text { Rahmaniet al. [38] }\end{array}$ & $\begin{array}{l}\text { stochastic bi-tier } \\
\text { method, } \\
\text { Branch-and-cut } \\
\text { algorithm }\end{array}$ & $\begin{array}{l}\text { Transmission expansion } \\
\text { planning problem }\end{array}$ & $\begin{array}{l}\text { The displaying of dynamic line rating to } \\
\text { represent the augmentation of the line } \\
\text { current-conveying limit in blustery } \\
\text { conditions }\end{array}$ \\
\hline 2013 & Dehghanianet al. [39] & $\begin{array}{l}\text { Straightforward } \\
\text { algorithm }\end{array}$ & $\begin{array}{l}\text { The quantitatively attack the } \\
\text { RCM implementation } \\
\text { problem by striving to frame }\end{array}$ & $\begin{array}{l}\text { Some upkeep activities and preventive } \\
\text { substitution are routinely done practically } \\
\text { speaking; due to the deferred } \\
\text { disappointments or put off restorative } \\
\text { systems of support, however, force a few } \\
\text { expenses }\end{array}$ \\
\hline 2012 & Manjureet al. & $\begin{array}{l}\text { MISO (Midwest } \\
\text { Independent } \\
\text { Transmission } \\
\text { System Operator) } \\
\text { method } \\
\end{array}$ & $\begin{array}{l}\text { AC power flow and stability } \\
\text { simulations to assure that } \\
\text { there are no voltage and } \\
\text { angular stability issues. }\end{array}$ & $\begin{array}{l}\text { The imperative arrangements in the } \\
\text { overhauled tax are the mutual system } \\
\text { updates, proposed to ease the free-rider }\end{array}$ \\
\hline 2014 & Molina et al. & $\begin{array}{c}\text { Modified } \\
\text { impedance matrix } \\
\text { method }\end{array}$ & $\begin{array}{l}\text { Allocate the transmission } \\
\text { cost problems }\end{array}$ & $\begin{array}{c}\text { Condition respective contracts and, } \\
\text { subsequently, it isn't suited for brought } \\
\text { together markets }\end{array}$ \\
\hline 2012 & $\begin{array}{c}\text { Nalinet al. , J. Nikoukaret } \\
\text { al. }\end{array}$ & $\begin{array}{l}\text { ANN, Tracing } \\
\text { Method }\end{array}$ & $\begin{array}{l}\text { Transmission cost } \\
\text { allocation problem }\end{array}$ & $\begin{array}{l}\text { Game theory based allotment technique is } \\
\text { the volume of information expected to land } \\
\text { at arrangement making it a troublesome } \\
\text { approach for continuous usage }\end{array}$ \\
\hline 2016 & $\begin{array}{l}\text { EnzeZhanget al., Di Bona et } \\
\text { al. }\end{array}$ & $\begin{array}{l}\text { PSO algorithm } \\
\text { and CFM }\end{array}$ & $\begin{array}{l}\text { Redundancy allocation } \\
\text { problem }\end{array}$ & $\begin{array}{l}\text { The tier of cynicism of chiefs ought to be } \\
\text { indicated already. }\end{array}$ \\
\hline 2016 & G. Kanagarajet al. & CS algorithm & $\begin{array}{l}\text { A nonlinear integer } \\
\text { programming problem }\end{array}$ & $\begin{array}{l}\text { TCO models arethe required extensive } \\
\text { accounting system to catch all the } \\
\text { important expenses of every provider }\end{array}$ \\
\hline 2016 & $\begin{array}{c}\text { Mostafa ArdakanAboueiet } \\
\text { al. , Yiwenet al. }\end{array}$ & GA & $\begin{array}{l}\text { Redundancy allocation } \\
\text { problems }\end{array}$ & $\begin{array}{l}\text { Nonlinear number improvement issues, the } \\
\text { conceivable blends to be considered are } \\
\text { more mind-boggling than widely examined } \\
\text { RAP with just single-utilitarian parts. }\end{array}$ \\
\hline 2016 & Chen et al. & OWA & $\begin{array}{l}\text { Reliability-based design } \\
\text { problems }\end{array}$ & $\begin{array}{l}\text { The average weighting allocation method, } \\
\text { an AHP-based method that combines the } \\
\text { MEMV-OWA operator in reliability } \\
\text { allocation }\end{array}$ \\
\hline 2016 & Khan et al. & LMBP & $\begin{array}{l}\text { Transmission loss and cost } \\
\text { allocation problems }\end{array}$ & $\begin{array}{c}\text { This method provide related results as a } \\
\text { prorata method but eliminates its flaws } \\
\text { drawbacks }\end{array}$ \\
\hline
\end{tabular}

Awadet al. [4] have established some allocating dispatch-able DG modules in power distribution network for frugally recuperate reliable system. The installing and operation of DG costs are to be highly optimized for accurate value to eliminate the power shortages. An efficient load model involves controlling the feasible size of DG unit's allocation. Da Silva et al. [5] have optimized an transmission cost allocating issues in both single and/or global energy markets. At first, the suggested technique permits the disintegration of the final cost into dual mechanisms: the primary relates the operated system capacity, valued at a detailed operating situation, the secondary furnishes the obtained capacity but unusual in system. 


\section{TRANSMISSION COST ALLOCATION METHODS}

Precise data of transmission practice is really significant due to application of highly used cost-allocation schemes. On another side, owing to non-linear type power-transmission equations, ideally problematic to decrease the power-flows in network modules related to discrete clienteles [6]. Instead, from an engineering viewpoint, it is thinkable and suitable to relate appropriate systems or guides to costing the impacts to the network. First, note that the sum of entire generations is equal to the sum of all demands and the losses. That is denoted by the equation (1).

$$
P_{G}=P_{D}+L
$$

Where,

$$
P_{G}=\sum_{i=1}^{N G} P_{G i} P_{D}=\sum_{j=1}^{N D} P_{D j}
$$

$P_{G}$ is total active power produced, $P_{G i}$ is power output of generators of bus i, $P_{D}$ is total active power demand, $P_{D j}$ is active power required by consumers of bus j, $L$ be transmission power losses, $N_{G}$ be a number of generating buses and $N_{D}$ be a number of demand buses. For effortlessness and without loss of generality, it is expected that in each bus there are at most one generator and one demand.

\section{A. Transmission cost unbundling and allocation}

The main loss-allocating of framework of global market which is allotted to each and every single modules such as generation units, loads, etc, which are restraint due to transmission losses [7]. Certainly, a N-node network system is signified by various nodal functions with several branches represented as equivalent model of $\pi$. The respective system functions with operating node, Nx1 nodal vectors in current functions are specified as below,

$$
I=Y E
$$

Where, $\quad I=\left[I_{1}, \ldots \ldots, I_{i}, \ldots \ldots \ldots, I_{N}\right]^{T}$ denotes the complex current injection vector, $E=\left[E_{1}, \ldots \ldots, E_{i}, \ldots \ldots \ldots, E_{N}\right]^{T}$ is the complex nodal voltage vector and $Y$ is the nodal admittance matrix. Next, the role of the current injection at the bus $b\left(I_{b}\right)$ to the current flowing through $r\left(I_{r}^{b}\right)$ branch can be processed as,

$$
\begin{aligned}
I_{r}^{b} & =A_{r} . \Delta E_{r}^{b}, \\
r & =1, \ldots \ldots, L, \quad b=1, \ldots \ldots \ldots, N
\end{aligned}
$$

Where, $\Delta E_{r}^{b}$ is the complex voltage drop thru branch $r$ caused by the current injection at bus $b$ and $A_{r}=y_{r}$ if the branch is a transmission line. So, TLoss can be described as,

$$
\text { TLoss }=\sum_{r=1}^{L} \text { Loss }_{r}
$$

In general, the allocation of total loss in transmission to attributed injection methodology to global market level as $b$ participant can be measured as follows,

$$
\text { PTloss }^{b}=\sum \text { Ploss }_{r}^{b}, \quad b=1, \ldots . ., N
$$

If the respective bus have both demand and generation capacity the loss allocated elements are categorized in a Pro-Rata strategy.

\section{B. Pro Rata (PR) allocation}

The PR strategy relatively appoints $50 \%$ of misfortunes to the requests and $50 \%$ to the generators, i.e.

$$
L_{G i}=\frac{L}{2} .\left(\frac{P_{G i}}{P_{G}}\right), \quad L_{G i}=\frac{L}{2} .\left(\frac{P_{D j}}{P_{D}}\right)
$$

Where, $L_{G i}$ are the losses allocated to the generator i, and $L_{D j}$ are the losses allocated to the demand $\mathrm{j}$.

\section{Marginal allocation (ITL)}

This system utilizes ITL (Incremental Transmission Loss) coefficients to relatively apportion misfortunes to generators and requests. ITLs are just gotten from a merged power flow. The ITL of a predetermined transport offers the adjustment in all-out misfortunes framed by an incremental change in the influence infused in that bus. In this way,

$$
K=\frac{\partial L}{\partial\left(P_{G i}-P_{D i}\right)}
$$

Where, $K_{i}$ is the ITL equivalent to bus $i$. It should be observed that the ITL of the slack bus is zero by definition. Lastly, losses allocated to each generator and demands are estimated by equation (8).

$$
L_{G i}{ }^{\prime}=P_{G i} \cdot K_{i}{ }^{\prime}, \quad L_{D j}{ }^{\prime}=P_{D j} \cdot K_{j}{ }^{\prime}
$$

It should be observed that this marginal procedure may assign negative losses to either generators or demands and these negative losses can be inferred as cross-subsidies.

\section{Unsubsidized marginal allocation}

The Unsubsidized ITL (U-ITL) procedure adjusts in a reliable way ITL coefficients in this way that negative misfortunes are stayed away from. Thus, an arrangement of ITLs is characterized for generators and a divergentone for requests. ITL coefficients, prepared for a given load bus, can just be signified to an alternate slack transport by characterizing an interpretation coefficient $\beta(0 \leq \beta \leq 1)$. The total losses can be ascertained as

$$
L=\sum_{i=1}^{N} K_{i}^{\prime} P_{i}
$$

Where, $N$ number of buses, $K_{i}^{\prime}$ normalized ITL coefficient of bus $\mathrm{i}$ and $P_{i}$ injected active power in the bus $i\left(P_{i}=P_{G i}-P_{D i}\right)$. 


\section{Proportional sharing allocation}

For the reader's convenience, this subclass fleetingly reviews Bialek's Proportional Sharing (PS) algorithm. Losses are first distributed to demands and then to generators. In regard to demands, a total gross demand with losses $P_{D}^{G}$ is defined as subsequent equation (10).

$$
P_{D}^{G}=P_{D}+L \text { and } P_{D}^{G}=\sum_{j=1}^{N_{D}} P_{D j}^{G}
$$

Where, $P_{D j}^{G}$ is the goes demand of bus j.

The proposed beneficiaries' procedure goal at reaching the transmission pricing is defined. It is modest to use and it has a suitable physical and economic supportive of the electricity transmission problems [8]. It delivers safe signals to agents building investment decisions, ensuring fairness, efficacy and steadiness in the resultant allocation. The technique reflects the line power flow as a portion of line use, worthy of use cost allocation function. Additional, it is supposed that maximum line flow condition line ability and investment costs. So, it is needed to control the system operating conditions that maximum flow in each line one at a time.

\section{ALTERNATIVE PRICING METHODOLOGIES}

This scheme provides the alternate pricing methodologies in open-market area definitely to eradicate the various issues in attaining use-based cost-allocating scheme [9]. It consisted of allocated un-subsidiary cost, un-using capacity of transmission level, MVA-Mile method and cost counter flows.

\section{A. Unsubsidized cost allocation strategies}

The new schemes furnishes the allocation of negative loss for respective participants and really explicable which reflects the losses in system and inconsistent in system over-all operations. Typically various injections are used but it affects the dominant power-flows and eliminated in opposite direction counter-flows [10]. This measured values of general system network and relies on definite injection process which enhances the performance of violation in loss allocation and attains high subsidiaries. Next, the initial unsubsidized loss allocation is calculated by equation (11).

$$
\begin{aligned}
& \text { Ploss }_{r}^{b}=\beta_{r} \text { ploss }_{r}^{b}+\left(1-\beta_{r}\right), \\
& \text { ifploss }_{r}^{b}<0, \quad r=1, \ldots . L ; \quad b=1, \ldots, N
\end{aligned}
$$

Where, $\beta_{r}$ be the translation coefficient for branch $\mathrm{r}$.

\section{B. Sharing loss allocation strategies}

An alternative feature of issues in loss-allocation due to various proportions which are in high loss qunatities acts as intermediate between custome and utility level. In various cases, the techno-economic issues are considered based on global participants, the final cost allocation consisted of generation buses only, and/or certain proportions attained by utility and customer level [11].

Thus, this intended scheme contains allocation type based on power partcipants relies on appropriate proportion to measure the loss measurement over the loads and generation

units [12], which furnishes the counter-flow issues, energy sharing subsidaries, etc.

\section{Unused transmission capacity}

The un-used transmission capacity is derived based on non-similarity capacity functions and actual power-flow on rated capacity [13]. In this method a MW-Mile methodology and feasible analysis of over-all transmission allocations costs are divided based on ratio of amplitude flow produced by respective transaction and addition of accurate power flows by every consumers. These equations furnishes the generalized expression of MW-Mile functions,

$$
T C_{t}=\sum_{k \in K} C_{K} \cdot\left(\frac{\left|F_{t, K}\right|}{\sum_{t \in T}\left|F_{t, K}\right|}\right)
$$

Where, $T C_{t}$ is the cost allocated to the transaction $t, C_{K}$ is the embedded cost of the facility $K,\left|F_{t, K}\right|$ is the magnitude of flow on facility $K$ caused by the transaction $t$, $K$ and $T$ denotes the sets of transmission facilities and transaction on the system [14].

$$
T C_{t}=\sum_{k \in K} C_{K} \frac{\left|F_{t, K}\right|}{\bar{F}_{K}}
$$

The cost-allocation is mainly consisted of two elements such as, $T C_{t}$ which is proportionality to used-capacity distributed to respective users in transmission level on actual power use. Another element $T S_{t}$ which is more insignificant over the final embedding costs and cost convalesced based on utilizing capacity. The usual co-pricing method can be described in (13). (14), and (15).

$$
\begin{gathered}
T S_{t}=q \Delta C \cdot\left(\frac{M W_{t}}{\sum_{t \in T} M W_{T}}\right) \\
\Delta C=\sum_{k \in K} C_{k}-\sum_{t \in T} T C_{t}
\end{gathered}
$$

\section{SIMULATION RESULTS AND ITS DISCUSSION}

In the table 2 displays that, the duration of load and the simulated load for 8-load states which are used in the MA-mile algorithm. Now, the weighted mean load values are considered by using the reliability system has been exemplified in figure 1 .

Table.2 Load duration and mean load for every simulated load methodology for the intended IEEE 24 bus system

\begin{tabular}{|c|c|c|c|c|c|c|c|c|}
\hline Load scenario & 1 & 2 & 3 & 4 & 5 & 6 & 7 & 8 \\
\hline \% peak load & 100 & $90-100$ & $80-90$ & $70-80$ & $60-70$ & $50-60$ & $40-50$ & $30-40$ \\
\hline Duration (H) & 2 & 118 & 968 & 1442 & 2034 & 1876 & 1977 & 319 \\
\hline $\begin{array}{c}\text { Weighted mean } \\
\text { load [Somanet } \\
\text { al.] }\end{array}$ & 100 & 92.57 & 83.85 & 74.95 & 64.82 & 54.65 & 45.50 & 37.80 \\
\hline
\end{tabular}




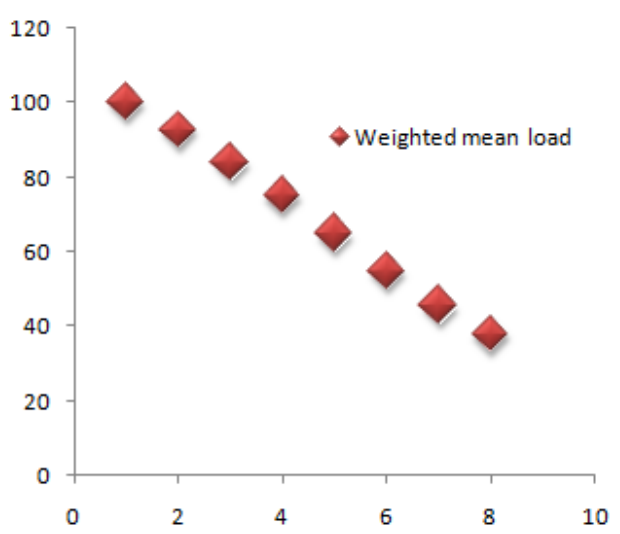

Figure.1Performance analysis of weighted mean load

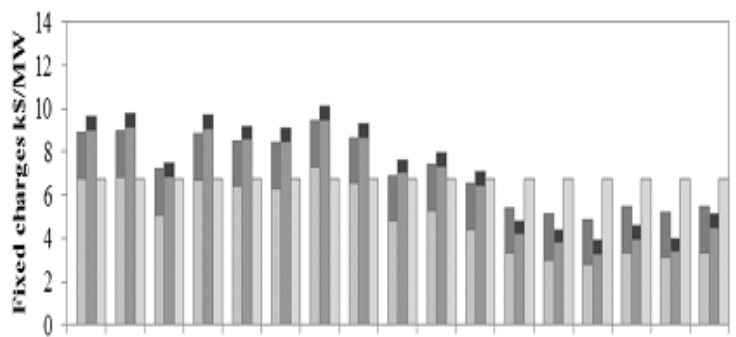

D1 D2 D3 D4 D5 D6 D7 D8 D9 D10 D11 D12 D13 D14 D15 D16 D17

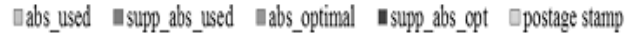

(a)

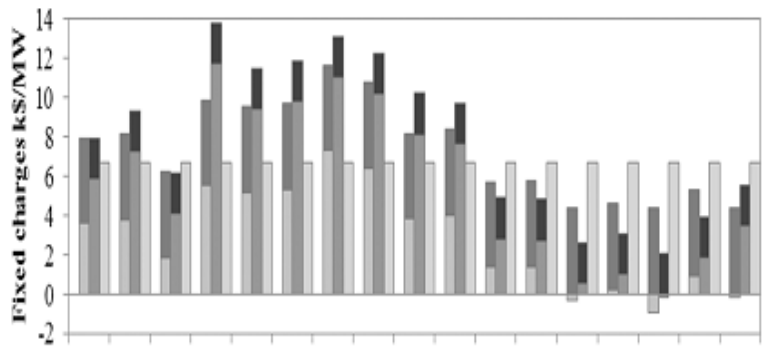

D1 D2 D3 D4 D5 D6 D7 D8 D9 D10 Dll D12 D13 D14 D15 D16 D17

Drev_used IIsupp__ev_used Irev_optimal Isupp_rev_opt apostage stamp

(b)

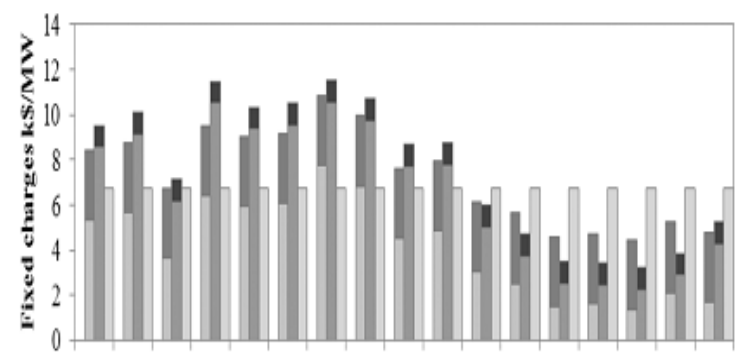

D1 D2 D3 D4 D5 D6 D7 D8 D9 D10 D11 D12 D13 D14 D15 D16 D17

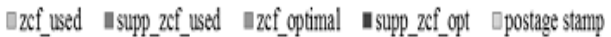

(c)

Figure.2 Consumer level cost charges (annually)/peak load situations based on the consumer level (a) Optimal Absolute and Absolute method, (b) Optimal Reverse and Reverse method, (c) Zero Counter-flow and its optimal method for IEEE-24 test system
The annual consumer level fixed charges based on peak load system attained based on absolute, reverse and optimal counter-flow methods are clearly analyzed in IEEE-24 bus system. in these MW-Mile of every superlative charge is analyzed based on postage stamp scheme. These charges highly resemble the allocated transmission stored capacity.

\section{A. Transmission reliability margin allocation}

Hereafter transmission reliability margin of lines $s \rightarrow b$ allocated to generator positioned at bus $i$ and $j$ are specified by equation (16) and (17).

$$
\begin{gathered}
T R M_{i-s \rightarrow b}^{1}=t_{i s} \text { trm } \\
T R M_{j-s \rightarrow b}^{1}=t_{j s} \text { trm }
\end{gathered}
$$

From the equations (16) and (17) TRM (Transmission Reliability Margin) are allocated to generators and loads correspondingly. From the table 3 it is detected that the generators which provide more power to line flows, have more TRM allocated. Likewise, table 3 delivers an association among TRM allocated by graph theory based matrices approach.

Table.3 Performance analysis of transmission reliability margin allocation

\begin{tabular}{|c|c|c|c|c|c|c|}
\hline \multirow{2}{*}{ Line } & \multicolumn{3}{|c|}{$\begin{array}{c}\text { TRM allocation by graph } \\
\text { theory based matrices method } \\
\text { [Orfanos } \text { et al.] }\end{array}$} & \multicolumn{3}{c|}{$\begin{array}{c}\text { TRM allocation by Bialek's } \\
\text { method [16] }\end{array}$} \\
\cline { 2 - 7 } & G1(pu) & G2(pu) & G3(pu) & G1(pu) & G2 (pu) & G3 (pu) \\
\hline 1 & 1 & 0 & 0 & 0.934546 & 0.003 & 0.062017 \\
& & & & & & \\
\hline 2 & 1 & 0 & 0 & 0.737646 & 0.221 & 0.041229 \\
\hline 3 & 1 & 0 & 0 & 0.78099 & 0.138 & 0.080909 \\
\hline 4 & 0.36632 & 0.63368 & 0 & 0.323005 & 0.289 & 0.078781 \\
\hline 5 & 0.36634 & 0.63366 & 0 & 0.800014 & 0.118 & 0.082555 \\
\hline 6 & 0.36602 & 0.63398 & 0 & 0.545261 & 0.300 & 0.154956 \\
\hline 7 & 0.36633 & 0.63367 & 0 & 0.273916 & 0.171 & 0.555305 \\
\hline 8 & 0.02 & 0.03 & 0.95 & 0.337897 & 0.194 & 0.468735 \\
\hline 9 & 0.02 & 0.03 & 0.95 & 0.253548 & 0.384 & 0.362786 \\
\hline 10 & 0.72381 & 0.27619 & 0 & 0.572841 & 0.285 & 0.141905 \\
\hline 11 & 0.6 & 0.15238 & 0.24762 & 0.301848 & 0.183 & 0.515473 \\
\hline Total & 5.82881 & 3.02357 & 2.14762 & 5.861511 & 2.286 & 2.544651 \\
\hline
\end{tabular}

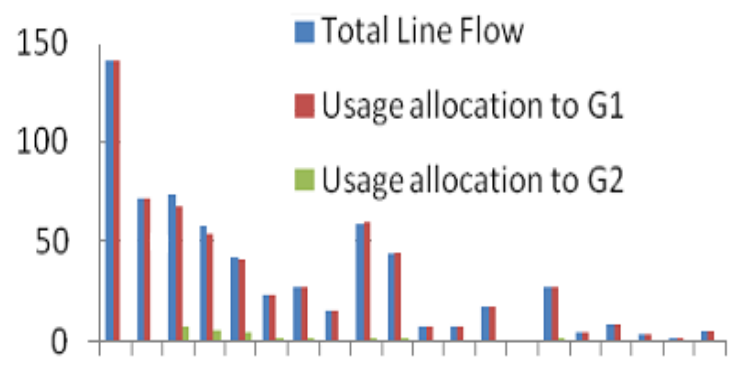

$\begin{array}{llllllllll}1 & 3 & 5 & 7 & 9 & 11 & 13 & 15 & 17 & 19\end{array}$

(a)

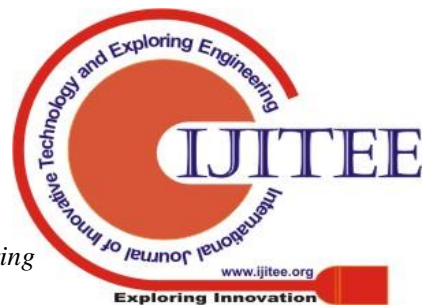




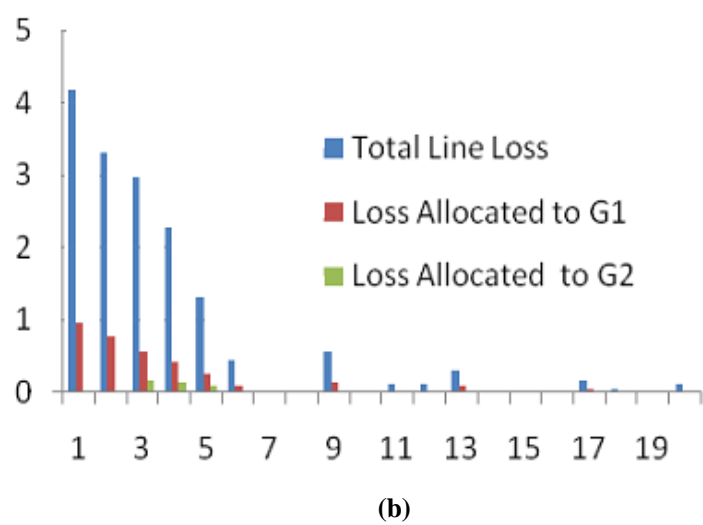

Figure.3 Performance analysis of generator shares to (a) line flow and (b) line loss

The graph theory based matrices technique is too used on IEEE 14 bus system. Now take on that cost of the line is proportional to the length of the line. Afterward, this share of each generator (load) in load (generator) and line flows are evaluated [17]. In figure 3 (a) stretches generators distribute numerous line flows consistently. Y-axis shows the usage allocation in MW and $\mathrm{X}$-axis offer number of lines. In figure 3 (b), performance analysis of generator delivers to line loss has been denoted. In the figure, total system losses arise in IEEE 14 Bus system is 15.87016 MW. $23 \%$ of total losses i.e. $3.70114478 \mathrm{MW}$ is allocated to generators and $77 \%$ i.e. 12.16902 is assigned to loads. In table 4, dissimilar TCA using Stragey plans 1-8 and many approaches to base loading condition for the 5-bus system has been executed.

Table.4 Different TCA using Stragey plans 1-8 and various method at base loading condition for the 5 -bus system

\begin{tabular}{|c|c|c|c|c|c|c|c|c|c|c|}
\hline Bus & $\begin{array}{c}\text { Strage } \\
\mathbf{y} \text { plan } \\
\mathbf{1}\end{array}$ & $\begin{array}{c}\text { Strage } \\
\mathbf{y} \text { plan } \\
\mathbf{2}\end{array}$ & $\begin{array}{c}\text { Strage } \\
\mathbf{y} \text { plan } \\
\mathbf{3}\end{array}$ & $\begin{array}{c}\text { Strage } \\
\mathbf{y} \text { plan } \\
\mathbf{4}\end{array}$ & $\begin{array}{c}\text { Strage } \\
\mathbf{y} \text { plan } \\
\mathbf{5}\end{array}$ & $\begin{array}{c}\text { Strage } \\
\mathbf{y} \text { plan } \\
\mathbf{6}\end{array}$ & $\begin{array}{c}\text { Strage } \\
\mathbf{y} \text { plan } \\
\mathbf{7}\end{array}$ & $\begin{array}{c}\text { Strage } \\
\mathbf{y} \text { plan } \\
\mathbf{8}\end{array}$ & $\begin{array}{c}\text { Postag } \\
\mathbf{e} \\
\mathbf{s t a m p} \\
\mathbf{m e t h o d}\end{array}$ & $\begin{array}{c}\text { Z-bus } \\
\mathbf{T C A} \\
{[\mathbf{1 8}]}\end{array}$ \\
\hline 1 & 341.25 & 117.6 & 209.2 & 233.72 & 231.9 & 160.02 & 383.21 & 372.66 & 301.82 & $\begin{array}{c}460.4 \\
7\end{array}$ \\
\hline 2 & 323.65 & 0 & 294.8 & 247.81 & 243.91 & 368.48 & 249.69 & 242.79 & 137.83 & $\begin{array}{c}239.8 \\
7\end{array}$ \\
\hline 3 & 136.34 & 259 & 151.6 & 127.43 & 129.5 & 186.43 & 198.75 & 207.74 & 131.25 & $\begin{array}{c}153.6 \\
3\end{array}$ \\
\hline 4 & 140.74 & 259 & 151.6 & 127.43 & 129.5 & 199.68 & 198.75 & 207.74 & 131.25 & 154.2 \\
8
\end{tabular}

In table 4, Stragey plan 1 allocates the most elevated cost for the generation bus system 1 which has the most astounding generation tier $(32.25 \%$ of the aggregate power age). Nonetheless, Stragey plan 2 allots the most elevated cost for the joint generator/stack at bus 5 which have the most astounding load tier ( $40 \%$ of the framework stack request) $[92,93]$. In Stragey plan 3, the most extreme TCA tier is at bus 2 which parallels $28.08 \%$ of the aggregate transmission use costs. In spite of the fact that different plans apportion diverse TCA tiers which are dependent upon the system topology, infused control at various transports and accentuation on current infusion. Plans $2-5$ assign the indistinguishable TCA tiers at buses 3 and 4 . Be that as it may, in Stragey plans 1 and 6 the TCA tiers at transports 3 and 4 are not comparable. These progressions are inferable from the system topology. The two Stragey plans 1 and 6 distribute the most elevated TCA at bus system 2 on account of the expansive number of lines identified with bus 2 . Likewise, plans 1 and 6 allots the most reduced TCA tiers at transport 5 related with another TCA plans. The Z-transport TCA technique dispenses the greatest TCA tier is apportioned at bus 1 (460.472 \$), which has the most elevated age tier, while the base TCA tier $(41.49 \$)$ is allotted at bus 5 which has the least power infusion tier. Stragey plan 7 has three contextual analyses. Each contextual investigation has two periods of TCA. Case 1 dispenses the transmission utilization costs with the littlest tier at transport 2 which has the most reduced load request and the biggest allotment tier at bus 5 which has the most elevated load request tier. At that point, Cases 2 and 3 dispense the transmission utilization costs with the littlest TCA tier is apportioned at bus 5, though the biggest TCA tier is distributed at bus 1. In Stragey plan 8, Cases 4 and 5 assign the transmission utilization costs with littlest portion tier at bus system 5 and the biggest designation tier at transport 1. Like Z-transport TCA technique, Stragey plans 7 and 8 assign a similar allotment tiers at stack buses 3 and 4 as practically identical as another plan expect the Z-transport TCA strategy.

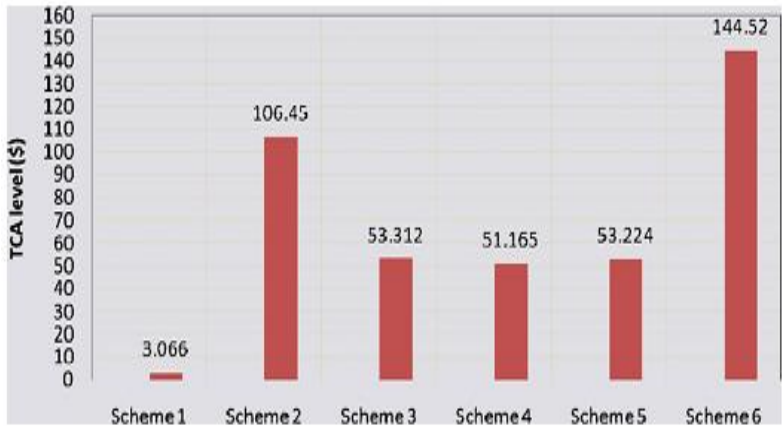

(a)

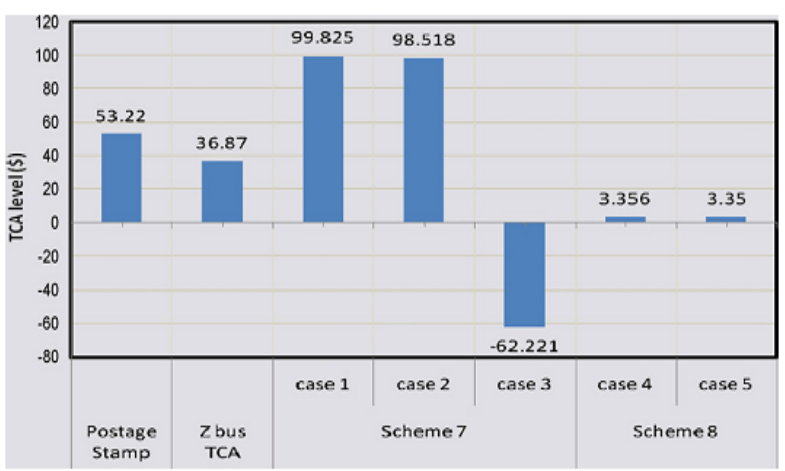

(b)

Figure.4 TCA tiers using Stragey plans (a) 1 to 6 and (b) 7 and 8 at base loading condition at bus 5 for the 14-bus test system

In figure 4 (a) and (b), transmission cost allocation tiers utilizing Stragey plans 1-8 at base stacking condition at bus system 5 for the 14-bus framework has been illustrated. In the overhead figure, like the TCA tiers at bus system 5 for various specified plans with the customary assignment strategies. Stragey plan 6 has the biggest TCA tier at the bus (144.52 \$). In conspire, 7, has the most minimal TCA tier at system $5(-62.221 \$)$. The negative TCA tier implies that: the ISO can console the buyer to take more power request to look at and share in discrete framework occasions.

\section{CONCLUSION}

In this paper, the reliability of transmission 
cost allocation strategy is highly studied based on transmission fixed charges relies on facilitated to greatest ideal limits. The TCA is giving the cost related security to the transmission arrange proprietor by giving assurance of income compromise. The investigation of the TCA demonstrates that absolute the variation of power flow is giving most elevated value contrasted with the dominant and reverse. The reverse variation of power flow utilized is demonstrating lessening in the net power course through the line. The transmission usage allocation issue can be followed by the voltage commitment from singular generators at each bus. The voltage commitment is dealt with as enhancement issue. In this view, transmission utilization of system charges ought to taken into effect the transmission framework usage and allocation the most extreme conceivable fixation cost of transmission by control flow based techniques. Since the above discussion, it is set up that meta-heuristic advancement methodology gives accurate and object situated results as differentiation to predictable systems.

\section{REFERENCES}

1. Moradi, Mohammad Hasan and M. Abedini, "A combination of genetic algorithm and particle swarm optimization for optimal DG location and sizing in distribution systems", An International Journal of Electrical Power \& Energy Systems, Vol.34, No.1, pp.66-74, 2012

2. Amanulla, B., SaikatChakrabarti and S. N. Singh, "Reconfiguration of power distribution systems considering reliability and power loss", IEEE transactions on power delivery, Vol.27, No.2, pp.918-926, 2012

3. Borges and Carmen Lucia Tancredo, "An overview of reliability models and methods for distribution systems with renewable energy distributed generation", An International Journal of Renewable and sustainable energy reviews, Vol.16, No.6, pp.4008-4015, 2012

4. Awad, Ahmed SA, Tarek HM El-Fouly and Magdy MA Salama, "Optimal distributed generation allocation and load shedding for improving distribution system reliability", An International Journal of Electric Power Components and Systems, Vol.42, No.6, pp.576-584, 2014

5. da Silva, Armando M. Leite, Joao Guilherme de Carvalho Costa and Luis Henrique Lopes Lima, "A new methodology for cost allocation of transmission systems in interconnected energy markets", IEEE Transactions on Power Systems, Vol.28, No.2, pp.740-748, 2013 Usaola, Julio, "A transaction-based method for allocation of transmission grid cost and losses", An International Journal of Electric power systems research, Vol.76, No.6-7, pp.395-403, 2006

6. Abdelkader and Sobhy M, "Transmission loss allocation through complex power flow tracing", IEEE transactions on Power Systems, Vol.22, No.4, pp.2240-2248, 2007

7. Mutale, J., G. Strbac, S. Curcic and N. Jenkins, "Allocation of losses in distribution systems with embedded generation", IET Proceedings-Generation, Transmission and Distribution, Vol.147, No.1, pp.7-14, 2000

8. Reta, R. and A. Vargas, "Electricity tracing and loss allocation methods based on electric concepts", IEE Proceedings-Generation, Transmission and Distribution, Vol.148, No.6, pp.518-522, 2001

9. Chung, Koo-Hyung, Balho H. Kim, Don Hur and Jong-Keun Park, "Transmission reliability cost allocation method based on market participants' reliability contribution factors", An International Journal of Electric power systems research, Vol.73, No.1, pp.31-36, 2005

10. Gross, George and Shu Tao, "A physical-flow-based approach to allocating transmission losses in a transaction framework", IEEE Transactions on Power Systems, Vol.15, No.2, pp.631-637, 2000

11. Mezger, Alfredo J. and Katia C. de Almeida, "Short term hydrothermal scheduling with bilateral transactions via bundle method", An International Journal of Electrical Power \& Energy Systems, Vol.29, No.5, pp.387-396, 2007

12. Roh, Jae Hyung, Mohammad Shahidehpour and Lei $\mathrm{Wu}$ "Market-based generation and transmission planning with uncertainties", IEEE Transactions on Power Systems, Vol.24, No.3, pp.1587-1598, 2009

13. Abhyankar, A. R., S. A. Soman and S. A. Khaparde, "Optimization approach to real power tracing: an application to transmission fixed cost allocation", IEEE transactions on power systems, Vol.21, No.3, pp.1350-1361, 2006
14. Conejo, Antonio J., Francisco D. Galiana and IvanaKockar, "Z-bus loss allocation" IEEE Transactions on Power Systems, Vol.16, No.1, pp.105-110, 2001

15. Kang, Qin-Ma, Hong He, Hui-Min Song and Rong Deng, "Task allocation for maximizing reliability of distributed computing systems using honeybee mating optimization", An International Journal of Systems and Software, Vol.83, No.11, pp.2165-2174, 2011

16. Orfanos, George A., Pavlos S. Georgilakis and Nikos D. Hatziargyriou, "A more fair power flow based transmission cost allocation stragey plan considering maximum line loading for $\mathrm{N}-1$ security", IEEE Transactions on Power Systems, Vol.28, No.3, pp.3344-3352, 2013

17. Abdala and Manuel A, "Transmission pricing in privately-owned electricity grids: An illustration from the Argentine electricity pool", An International Journal of Energy Economics, Vol.30, No.4, pp.1284-1305, 2008

18. Radzi, N. H., R. C. Bansal, Z. Y. Dong, M. Y. Hassan and K. P. Wong, "RETRACTED: An efficient distribution factors enhanced transmission pricing method", An International Journal of NEM transmission charging stragey plan, pp.319-328, 2013

\section{AUTHORS PROFILE}

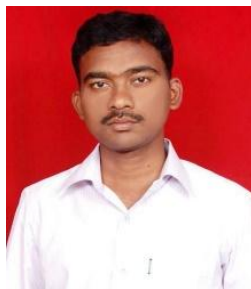

SHAIK. MUQTHIAR ALI obtained his Bachelor's degree in Electrical and Electronics Engineering from Madina Engineering College, Affiliated to JNTU, Hyderabad. Then he obtained his Master's degree in Electrical Power Systems from Sree Vidyanekithan Engineering College affiliated to JNTU, Hyderabad. Currently, he is a pursuing Ph.D at JNTUA, Ananthapuramu. $\mathrm{He}$ is working as Asst. Professor in Annamacharya Institute of technology and Sciences Rajampeta. His current research interests are Deregulation, Power Quality.

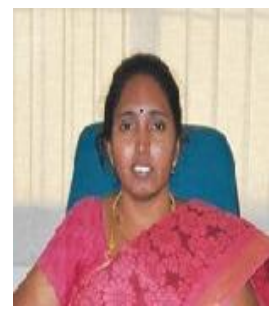

Dr. Mareddy Padma Lalitha received the B.Tech degree from the JNTU College of Engineering, Ananthapuram, M.Tech \& $\mathrm{PhD}$ Degree from S. V. University, Tirupati in 2002 and 2011. She is currently working as Professor and Head of the Department in Electrical and Electronics Engineering Annamacharya Institute of technology and Sciences Rajampeta. Her research interests are Distributed Generation, Power Quality, Facts, Soft computing Techniques

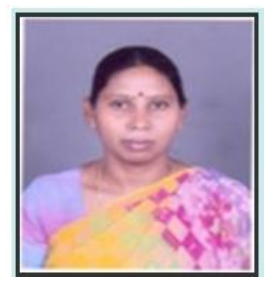

Dr. N. Visali received the B.Tech degree from the JNTU College of Engineering, Ananthapuram, M.Tech from Karnataka Regional Engineering College in the year $1998, \mathrm{PhD}$ Degree from JNTU A , Ananthapuramu in 2013. She is currently working as Professor, Vice Principal and Head of the Department in Electrical and Electronics Engineering in JNTUACEK, Kalikiri. Her research area is electrical distribution systems, Energy systems. She has published more than 20 technical papers in various international and national journals \& presented many papers in national and international conferences in India and abroad. 